\section{REFERENCES} Amos, D. B., Nicks, P. J., Peacocke, N., and Sieker, H. O. (1965). F.

Bach, F., and Hirschhorn, K. (1964). Science, 143, 813.

Bain, B., Vas, M. R., and Lowenstein, L. (1964). Blood, 23, 108.

Bateman, A. J. (1965). Lancet, 1, 1117. Berroche, L., Maupin, B., Hervier, P., and Dausett, J. (1955). Vox Sang.
(Basel), 5, 82.

Brent, L., and Medawar, P. B. (1963). Brit. med. 7., 2, 269.

Bridges, (1964). Nature (Lond.), 204, 90.

Bridges, J. M., Nelson. S. D., and McGeown, M. G. (1964). Lancet, 1,

Elves, M. W., and Isıaëls, M. C. G. (1965). Ibid., 1, 1184.
Hamburger, J., Crosnier, J., and Dormont, J. (1965). Ibid., 1, 985.

Hirschhorn, K., Bach, F., Kolodny, R. L., Firschein, I. L., and Hashem, N. (1963).' Science, 142, 1185 .

Irvine, K. N. (1954). B.C.G. and Vole Vaccination. National Association for the Prevention of Tuberculosis, London.

McFarland, W., and Heilman, Dorothy H. (1965). Nature (Lond.), 205, 887.

Moorhead, J. F., and Patel, A. R. (1964). Brit. med. f., 2, 1111.

Pearmain, G., Lycette, R. R., and Fitzgerald, P. H. (1963). Lancet, 1, 637.

van Rood, J. J., and van Leeuwen, A. (1963). . . clin. Invest., 42, 1382. Bernisse, J. G., Frederiks, E., and Bosch, L. J. (1964). Ann. Acad. Sci. 120, 285

Simonsen, M. (1965). Lancet, 1, 415.

\title{
The Epping Jaundice
}

\author{
H. KOPELMAN,* M.D., F.R.C.P. ; M. H. ROBERTSON, $†$ M.B., CH.B., M.C.PATH. \\ P. G. SANDERS, $\ddagger$ M.A., A.R.I.C. ; I. ASH,§ M.D., D.P.H.
}

Brit. med. F., 1966, 1, 514-516

Early in February 1965 one of the medical students attached to St. Margaret's Hospital, Epping, reported sick with a history of severe upper abdominal pain of two days' duration followed by mild jaundice. At about the same time a woman anaesthetist married to a local general practitioner presented with similar symptoms. Soon after this several other cases appeared with jaundice, some with pain, others with discomfort, and it became apparent that these were not cases of biliary obstruction or of infectious hepatitis.

The general practitioners in the area were asked to report similar cases, and it was soon obvious that a local outbreak of jaundice was occurring which did not conform to any known clinical picture.

\section{Clinical Presentation}

Patients presented in three ways. The commonest form had an acute onset with severe intermittent pain in the upper abdomen and lower chest, mainly towards the right side. This could be severe and last from 24 to 36 hours, after which it was often noted that the motions were pale and the urine was dark. During the next four to five days these patients improved but still felt unwell, and then many of them became pyrexial with 'flu-like generalized aches and pains, rigors, and increasing jaundice. On examination the liver was enlarged and tender, occasionally reaching $3-4$ in. (7.5-10 cm.) below the costal margin. The spleen was never palpable. This condition lasted a few days and was followed by general improvement, the liver becoming smaller and less tender, though the jaundice persisted in many cases for weeks, with pruritus nearly always present during the whole period. Despite being jaundiced the patients now felt better and had a good appetite but were not really well for some considerable time.

Other cases, often in the families of those described above, had only vague initial symptoms of upper abdominal discomfort, not severe enough to seek medical attention. About a week later, however, these too developed pyrexia, generalized aches, and increasing jaundice similar to the second phase in those previously described. On the whole jaundice persisted longer in these patients.

\footnotetext{
* Physician, St. Margaret's Hospital, Epping.

† Pathologist, St. Margaret's Hospital, Epping.

¥ Biochemist, St. Margaret's Hospital, Epping.

$\checkmark$ Medical Officer of Health, Epping and Harlow Urban District Councils and Epping and Ongar Rural District Council.
}

The third and least common type of onset was in some elderly patients who, when first seen, had severe jaundice but gave a history of only minimal preceding symptoms. The liver in these patients was often greatly enlarged but was rarely tender on palpation.

\section{Incidence and Clinical Findings}

We have records of 84 persons who were affected by the disease. None of them had any relevant drug history prior to the illness. In 50 the onset was acute with fairly severe colicky pain of the type described, 29 had the more insidious onset, and only five presented with severe jaundice and minimal preceding symptoms. Fifty-seven of these patients were more fully investigated.

The degree of jaundice varied considerably. The highest serum bilirubin in the series was $29.3 \mathrm{mg} . / 100 \mathrm{ml}$. The jaundice was usually much milder, however, and 35 patients had serum bilirubin levels under $5 \mathrm{mg} . / 100 \mathrm{ml}$., 14 between 5 and $10 \mathrm{mg} . / 100 \mathrm{ml}$., and only three had values of $20 \mathrm{mg}$./ $100 \mathrm{ml}$. or more. All the patients showed some rise in the serum alkaline phosphatase level, the highest being $84.5 \mathrm{~K}$.A. units/100 ml., 22 having values between 20 and 30 K.A. units/ $100 \mathrm{ml}$., and 23 being below 20 K.A. units $/ 100 \mathrm{ml}$. The thymol turbidity test was normal in all cases. The serum glutamic oxaloacetic transaminase level was invariably raised, in most instances to between 40 and 50 Karmen units, and took some time to settle to normal. Occasionally values of over 200 Karmen units were obtained early in the disease, while a few cases showed a secondary peak during recovery.

Needle biopsy of the liver was performed in four cases within two to three weeks of the onset of symptoms. All the biopsies showed cellular infiltration and cholestasis. There was evidence of damage both to the liver parenchyma and to the biliary tree. In two cases cholangitis was apparent. These findings were unique and differed from those produced by known infective, toxic, or therapeutic agents in man. A detailed description of the cases and biopsy findings will be published separately (Kopelman, Scheuer, and Williams, 1966).

At first an infective basis for the disease was suspected and investigations were instituted with this in mind. The PaulBunnell test was performed on 12 patients and was negative, as was the Brucella abortus agglutination test on 13. The results of investigations for the presence of enterovirus in stools 
from 15 patients carried out by Dr. Y. E. Cossart, of the Virus Reference Laboratory, were also negative. In view of an outbreak of fascioliasis in Hampshire (Facey and Marsden, 1960) nine patients' stools were examined for liver-fluke ova. None was found. This was confirmed by Dr. D. S. Ridley, of the Hospital for Tropical Diseases, who also obtained negative results from the fasciola complement-fixation test on six sera. The leptospira agglutination test was negative in four sera examined by Dr. L. H. Turner, of the Leptospirosis Reference Laboratory.

All but two patients recovered completely after jaundice of from two to several weeks, the liver-function tests returning to normal. These two patients had persistent severe jaundice after three months but subsequently showed signs of rapid improvement.

\section{Epidemiology}

It was soon apparent that not only was the disease itself uncommon but it was showing an unusual choice of victim and a restricted geographical area of occurrence. Thus it mainly affected adults, including a high proportion of pairs such as husband and wife or mother and daughter living together. A large proportion of patients belonged to the professional class, and members of a pair often fell ill within a short time of each other. The first cases were reported from Epping and the immediate neighbourhood, but subsequently a number came to light in Ongar, seven miles to the east, and in places within easy reach of these two towns.

The medical student, who was the first to present with the disease, was obviously an important lead, since his attachment to St. Margaret's Hospital began on 1 February 1965 and he developed symptoms on 5 February during a week-end spent at his home in Harrow. His wife subsequently became jaundiced, her symptoms having been more insidious at the start. The only connexion established between her and Epping was a loaf of wholemeal bread, purchased by the husband and taken home by him, which both had eaten. As bread is so rarely responsible for food-poisoning this clue was not pursued at first, and other diseases with short incubation periods and acute pain, such as Coxsackie virus infection, were considered. Subsequently the sister in charge of the ward in which several affected patients were being nursed was herself affected by the disease. Careful questioning showed that she too had eaten similar wholemeal bread. Direct questioning of all the other patients in hospital, or ill at home with similar symptoms, revealed that all those known to be affected had eaten this same type of bread.

Inquiry showed that this particular wholemeal bread was produced by an Epping bakery, and immediately the baking of this bread was suspended and all unused flour and unsold loaves were removed. Up to this time 27 loaves a week had been baked, and some of these were sold in a branch shop in Ongar. It was a type of coarse brown bread eaten mainly by those who had acquired a taste for it ; children seldom liked it. These features fitted well with the known distribution of the jaundice.

Two small pieces of the suspected bread were recovered from patients' homes, and, to establish that it contained a substance capable of producing liver damage, six young male white mice were fed $a d l i b$. on a diet consisting entirely of some of this bread and water for periods of two to ten days. The remainder of the bread was sent for chemical analysis. One mouse was killed and examined on the second day and subsequently one on each following second day. Two similar mice were used as controls, and, having been fed on ordinary white bread, were killed after 10 and 35 days. The group of mice fed on the suspected bread developed hepatic lesions consisting of small foci of liver-cell necrosis, round-cell infiltration of the portal tracts, and early biliary duct hyperplasia. The livers of the control animals were not affected.
Originally a chemical cause for the jaundice was considered as well as infective agents, but now chemical contamination of the flour was urgently investigated. In the mill from which this flour came all wheat is ground in the same way, no matter for what purpose the flour is intended, but, for this particular wholemeal, bran and other substances are added and the mixture is distributed under a trade name to bakers throughout the country. Since inquiries to the medical officers of health of other areas where flour of the same batch was delivered revealed no other outbreak, it was concluded that only the flour delivered to the Epping bakers was contaminated. The incidence of cases (see Chart) shows that the first symptom of the disease was noted in two instances on 1 February and that the greatest number of cases occurred between 4 and 10 February. A bag of the wholemeal was received at the bakery on 21 January, but was not used immediately as there was about a week's supply in stock. This bag of meal was subsequently tipped into a bin and baking began just prior to the appearance of the first cases. It seemed likely that the contaminant was maximal in the portion at the top of the bin (the bottom of the sack) and diminished as the meal was subsequently used.

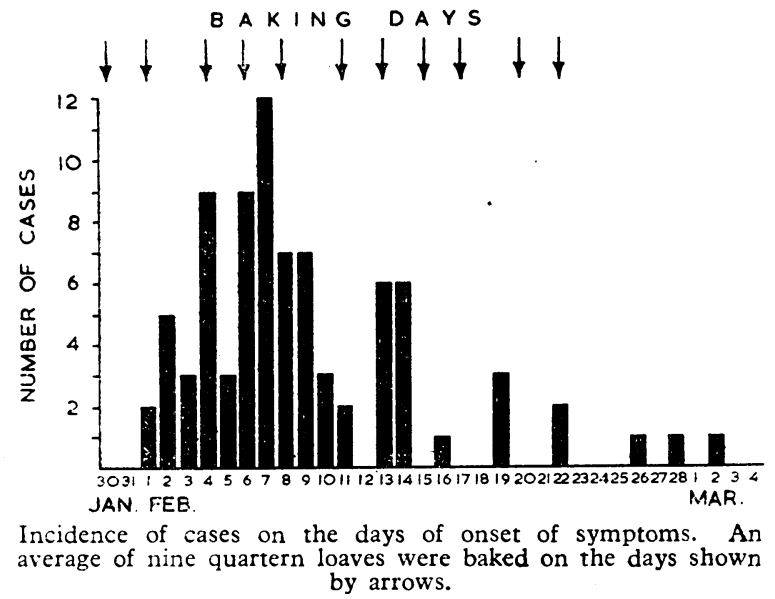

Several close inspections of the bakery showed that no contamination had occurred there ; similarly, it was established that there had been no contamination prior to the dispatch of the meal from the distributor. Attention was directed, therefore, to the transport of the sack of flour to the bakery. It had been conveyed by a firm of general carriers, together with miscellaneous other goods. A list of these carried on 21 January and on the preceding 10 days was obtained, and it was found that on each of these days the van carried articles from a large chemical manufacturing company. Many different chemicals were involved and it took a considerable time to obtain a complete list of them. Both carrier and chemical firm could not at first ascertain whether any of the packages had been damaged. Subsequently, after persistent inquiry, it was learned that on the day the flour was transported, 21 January, a plastic jar containing a liquid had fallen and the cap had come off, spilling the contents in the van. Although two paper bags holding other goods were seen to be wet and stained and were returned to the sender, it was not noticed that the hessian flour-bag was affected in any way. It should be remembered that the sack of flour was retained in the warm bakery for about a week before being opened, allowing ample time for the liquid to be absorbed by the flour and for the sack to dry.

The substance which was spilled was a hardener for epoxy resin consisting of 4,4'-diaminodiphenylmethane, an aromatic amine, dissolved in butyrolactone.

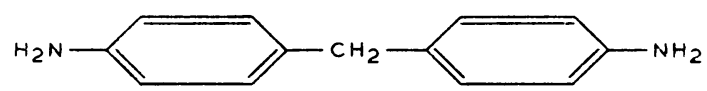

The pure amine, recrystallized from benzene, consists of pale yellow crystals (melting-point $93^{\circ}$ C.). Its chemical properties 
are typical of the aromatic amines. The free base is almost insoluble in water but readily dissolves in a trace of acid.

While clinical and epidemiological inquiries were proceeding some of the unused wholemeal, samples of the unsold loaves, and small portions of bread recovered from patients with the disease had been sent for analysis to a public analyst and to the M.R.C. Toxicology Research Unit at Carshalton. Dr. J. H. Hamence, the public analyst for Epping, was able to exclude contamination with seeds of weeds of the Compositae family and alkaloids derived from these, metallic poisons including arsenic, and agricultural pesticides. He found, however, a small amount of an unidentified base, not normally present in brown loaves. Simultaneously, Dr. Regina Schoental, of the M.R.C. unit, had extracted the affected bread with methanol, removed the solvent in vacuo, and obtained a yellow deposit. This substance, suspended in alcohol and given to two white mice by stomach-tube, caused liver changes among other toxic manifestations. Another portion of the extract examined by paper chromatography with butanol acetic acid as solvent produced a spot staining brownish-blue with ninhydrin. When samples of the hardener were sent to the two laboratories it was confirmed by both that it was identical with the unknown constituent present in the bread. Dr. Hamence estimated that the sample of wholemeal bread contained $0.26 \%$ of the amine when the moisture content of the bread sample was $11.5 \%$. The sample of meal contained only 13 parts per million, 1/200th of that in the bread. The meal was, however, that taken from the bottom of the bin, while the bread had been prepared from that taken near the top.

This substance darkens considerably on exposure to light, as was noted in the chromatographic spot originally obtained from the suspected bread. The bread being brown in colour, any such change was not noticed. One person is known to have tasted the bread and to have spat it out, saying it was bitter and unpleasant. He did not develop the disease.

\section{Discussion}

Jaundice due to drugs and toxic substances has in recent years become of increasing frequency and importance. The presenting features of the Epping jaundice did not follow any known pattern of disease due to these causes. The severe upper abdominal pain, sometimes occurring only hours after eating the contaminated bread, simulated biliary obstruction, and the rise in serum alkaline phosphatase and persistent pruritus further supported this diagnosis. The needle liver biopsies, however, showed unique histological appearances with hepatocellular damage, cholestasis, and cholangitis. Jaundice due to chlorpromazine most closely resembles this clinical and histological picture (Cook and Sherlock, 1965), but the onset, course, and histology of the disease in this outbreak were essentially different.

Outbreaks of chemical food-poisoning are much less common than those due to bacterial agents, and bread has rarely been the vehicle for either. Sapeika (1952) and Watt and BeyerBrandwijk (1962) reported an outbreak of food-poisoning in South Africa due to alkaloids of senecio seeds (Compositae family) contaminating bread. The ever-widening use of chemicals in agriculture has increased the risk of grain becoming affected. Fungicidal agents used for seed-dressing have been responsible for outbreaks of poisoning in Turkey, Iraq, and Pakistan, where grain intended for planting found its way into bakeries and private households (Schmid, 1960; Jalili and Abbasi, 1961 ; Haq, 1963). El-Din Mustafa (1960) described an outbreak of chemical food-poisoning which affected 257 persons and was caused by an organophosphorus insecticide, parathion, which had accidentally contaminated bread, probably during its preparation. In this country Davies and Lewis (1956) described an outbreak of food-poisoning due to bread made from flour contaminated with endrin, another insecticide.
This incident is similar to the Epping outbreak inasmuch as the flour became contaminated in transit, though in this case from the floor of a railway truck in which the toxic agent had spilled some days before the flour was carried.

There has been no previous record of human poisoning with $4,4^{\prime}$-diaminodiphenylmethane. It is noteworthy that the manufacturers supplied the information that while their material is of low toxicity to small rodents it produces liver and kidney damage when administered to dogs and cats in fairly high dosage and can be absorbed through the skin of rabbits when dissolved in suitable solvents. Impairment of hepatic function was observed in cats on daily oral doses of as little as $3 \mathrm{mg} . / \mathrm{kg}$.

Our findings may be at variance with those of the makers regarding small rodents, but our experiments to date have been concerned only with early changes after feeding small amounts for a short period. The mice have shown hepatic changes similar to, but not identical with, those seen in the human biopsy specimens. There is evidence to suggest that these changes are reversible. A fuller account of these mouse experiments is in preparation. It is of interest that Zylberszac (1951) described "la cirrhose hépatique" occurring in rats given implantations of this aromatic amine. Though this product has been produced and used for many years, no toxic effects have been described in human beings so far as can be ascertained. Scott (1962) states that no cases of chronic liver damage due to exposure of workpeople to aromatic amines have yet been reported from a factory anywhere in the world, but the liver could possibly be involved if very heavy exposure induced acute poisoning. This is extremely rare. He gives the warning that more information is required on the effect of aromatic amines on the human liver before one can dismiss the possibility of chronic hepatic damage in heavily exposed workmen.

\section{Summary}

An outbreak of jaundice occurred in the Epping district of Essex in February 1965. Eighty-four persons are known to have been affected and the clinical presentation, investigations, and course of the disease are briefly described. Liver biopsy showed unique histological features.

All those affected had eaten wholemeal bread made at an Epping bakery. A sack of flour from which the wholemeal bread was made had been delivered to the bakery in the same van as that used on the same day for transporting a plastic jar containing 4,4'-diaminodiphenylmethane, which was found to have been spilt in the van.

Investigations leading to the identification of this substance in the bread are briefly described.

In addition to the people mentioned in the text we are grateful especially to the general practitioners of Epping and Ongar for their help and co-operation; to Drs. R. Williams and P. Scheuer, of the Royal Free Hospital, for assistance with the liver biopsies; to Dr. I. M. Tuck and Mr. J. E. S. Whitney, of Epping, for help and advice ; and to the laboratory staff of St. Margaret's Hospital for technical work.

We also wish to record our appreciation of the full assistance afforded us by all the firms and organizations involved.

\section{REFERENCES}

Cook, G. C., and Sherlock, S. (1965). Lancet, 1, 175.

Davies, G. M., and Lewis, I. (1956). Brit. med. F., 2, 393.

El-Din Mustafa, M. N. (1960). F. Egypt. med. Ass., 43, 861.
Facey, R. V., and Marsden, P. D. (1960). Brit. med. J., 2, 619.

Haq, I. U. (1963). Ibid., 1, 1579 .

Jalili, M. A., and Abbasi, A. H. (1961). Brit. F. industr. Med., 18, 303.

Kopelman, H., Scheuer, P., and Williams, R. (1966). To be published.

Sopeika, N. (1952). S. Afr. med. F., 26, 485.

Schmid, R. (1960). New Engl. F. Med., 263, 397.

Scott, T. S. (1962). Carcinogenic and Chronic Toxic Hazards of Aromatic Amines. Elsevier, Amsterdam and New York.

Watt, J. M., and Beyer-Brandwijk, M. G. (1962). The Medicinal and Poisonous Plants of Southern and Eastern Africa, 2 nd ed. LivingPoisonous Plants of Southern
stone, Edinburgh and London.

Zylberszac, S. (1951). C.R. Soc. Biol. (Paris), 145, 136. 